\title{
PUSH-OVER method for earthquake damage prediction of Bridge Engineering
}

\author{
Qi Jingjing ${ }^{1,}$, Yin Zhiqing ${ }^{2, b}$ and Wu Kongbing ${ }^{3, c}$ \\ ${ }^{1}$ Shengli Oilfield Technology Inspecrtion Center, SINOPEC; Shandong Dongying, China \\ aqijingjing533.slyt@sinopec.com, byinzhiqing685.slyt@sinopec.com, \\ cwukongbing.slyt@sinopec.com
}

\begin{abstract}
Keywords: bridge structure; earthquake disaster prediction; push-over method
Abstract. The bridge is an important transportation hub, especially the bridges on the main traffic arteries. Once the bridges are subjected to earthquake damage, there will have a great impact. Therefore, it is necessary to study the earthquake damage prediction of bridge engineering. The prediction will ensure the safety and reliability of the bridges and other lifeline engineering. And we can take the necessary measures to mitigate disasters according to the prediction results. So the PUSH-OVER method for earthquake damage prediction of bridge engineering is put forward in this paper. And the domestic and foreign research results of seismic resistance of the bridge engineering are combined in this method. Taking a large bridge project as an example in this paper, the anti-seismic checking calculation of the bridge is carried out. And the seismic performance evaluation results are obtained through the checking calculation.
\end{abstract}

\section{Introduction}

The bridge is an important part of the lifeline engineering, it is the main hinge of transportation. And the bridge lies in an extremely important position in the earthquake relief work. Once the bridges ,especially the bridges on the main line, are damaged by earthquake action, there will have a significant impact on the social, political, economic, etc. And it will also bring great difficulties to the earthquake emergency and post earthquake recovery work. Therefore, the actual earthquake damage prediction of the bridge engineering will provide a reliable basis for the preparation of urban earthquake disaster prevention planning. And it is also an important work to improve the urban comprehensive earthquake disaster reduction ability. Taking a large bridge project as an example in this paper, the earthquake damage prediction of bridge is carried out. According to the results of the calculation and the domestic earthquake disaster experience of bridge engineering, the seismic damage prediction results are put forward.

\section{PUSH-OVER method for earthquake damage prediction of Bridge Engineering}

PUSH-OVER method is a kind of nonlinear static analysis method, which is based on the analysis of the structure imposing monotonic increasing load. The method can be used to study the nonlinear performance of the structure under seismic excitation into the plastic collapse state. In this method, the structure of adjacent expansion joints is considered as the independent frame of space. And it is assumed that the upper structure is relatively rigid in the horizontal plane.

The initial stage of the analysis is to analyze the independent collapse process of the single row in the direction of the concerned, the direction of the bridge or the transverse direction of the bridge. Through the analysis, the whole damage process and deformation characteristics of the component under monotonic increasing horizontal load are obtained. The monotonic increasing horizontal force is applied on the frame center of mass, it is usually the center of mass of the upper structure. And with the nonlinear development of the framework, the stiffness of the bridge pier and the stiffness of the structure are constantly adjusted, until the structure reaches the ultimate limit state.

For the considered limit state or damage grade, the equivalent elastic response inertia force can be defined as: 


$$
V_{\varepsilon}=\min \left|\frac{\Delta_{i}}{\delta_{i}}\right|_{i}
$$

1)

In the formula, $\delta_{i}$ represent the displacement of the top of pier i induced by the inertial force acting on the frame of mass center of the frame, and $\delta_{i}$ is initial displacement; $\square$ i represent the corresponding displacement of the pier top.

$$
V_{\varepsilon}=\min \left|\frac{\Delta_{i}}{\delta_{i}}\right|_{i}
$$

Through the formula, the most dangerous state of the pier can be given. Assuming that the linear dynamic response and nonlinear dynamic response can meet the maximum displacement equivalent criterion. According to the structural displacement ductility factor of the frame under the limit state or failure level, the equivalent elastic response level $V_{E}^{*}$ can be defined as:

$$
V_{E}^{*}=V_{E} \frac{Z}{\mu_{\Delta}}
$$

In the formula, $\mathrm{Z}$ is reduction factor, and which can be calculated by the following formula:

$$
Z=0.67\left(\mu_{\Delta}-1\right) \frac{T}{T_{0}} \leq \mu_{\Delta}
$$

In the formula, $\mu_{\Delta}$ represents structural ductility factor, $T_{0}$ represents the corresponding period of the peak value of the site elastic response spectrum. T refers to the first order elastic period of the structure, which is obtained from the initial stiffness and quality of the framework.

Defines $\mathrm{W}$ as the effective quality of the framework, the equivalent elastic response acceleration $\mathrm{S}(\mathrm{g})$ can be defined as:

$$
S(g)=\frac{V_{c}^{*}}{W}
$$

By comparing the $\mathrm{S}(\mathrm{g})$ with the acceleration response spectrum used to evaluate, the limit state or deformation grade of the structure can be obtained. The acceleration response spectra for evaluation can use the standard response spectrum obtained from the field of seismic hazard analysis or the design response spectrum provided by specification. The peak of ground motion acceleration and seismic intensity are converted by $\operatorname{lga}=0.3 \mathrm{I}$.

\section{Engineering projects}

Survey of a highway bridge. A highway bridge is built in 1987, which is a steel cable-stayed bridge. The maximum span of the bridge is $288 \mathrm{~m}$, and the full length of the bridge is $2817 \mathrm{~m}$. The length of the approach bridge is $2135 \mathrm{~m}$, and the length of the main bridge is $682 \mathrm{~m}$. And there are 24 holes on the south bank, and 47 holes on the north bank. The span of the bridge is $60.5+136.5+288+136.5+60.5 \mathrm{~m}$, and the width of the bridge is $19.5 \mathrm{~m}$. The orthotropic double steel box girder and portal twin towers are used in the main bridge. The tower and beam are separated in the bridge, and the stay cables are fan-shaped arranged. The cable distance is $12 \mathrm{~m}$. The towers of the bridge are hollow variable cross-section. And the structure of the towers is the combination of the steel box and C40 concrete. The anchoring section of the bridge is $\mathrm{H}$ section. The height above the cushion cap is $69.7 \mathrm{~m}$, and the height above the bridge deck is $56.4 \mathrm{~m}$. The foundation of the bridge is composed of 22 bored piles of $1.5 \mathrm{~m}$ diameter. And the length of the piles are all $96.5 \mathrm{~m}$. The approach bridge is a deck continuous beam bridge. The span of the bridge is $30 \mathrm{~m}$. The pre-stressed concrete monolithic box girders are used in the bridge. The piers are three-column piers, and the height of the piers is $9 \mathrm{~m}$. The foundations of the piers are bored pile foundation. 
The design load standard of the bridge is car-super20, trailer-120. And the earthquake resistance of the bridge is 7 degrees. The soil type of the field is III.

\section{Bridge seismic damage prediction.}

Qualitative evaluation. The longitudinal reinforcement ratio of the main bridge pile foundation is $0.7 \%$. The detail structures and so on are all meet the construction requirements of class B in 7 degree area, which is specified in 《Design code for anti-seismic of special structures》. The pile foundation is buried deep (about $100 \mathrm{~m}$ ), which is extremely beneficial to the earthquake resistance.

Refer to the guidelines for anti-seismic design of highway bridges draw up by Application Technology Committee in the United States of America, the bridge is in line with pile foundation seismic structural requirements of the B type of bridge, in addition to the bridge cap and pile cap joints. The joints are not set hoop reinforcement. The PTFE sliding plate rubber bearings are used in the towers of the main girder, and the semi floating cable-stayed bridge is composed. Because the first order natural vibration period is longer(about $5 \mathrm{~s}$ ), the level of seismic force is reduced effectively.

Quantitative evaluation. The PUSH-OVER method is used in the quantitative evaluation of the main bridge.

The dynamic calculation model of the main bridge: The full bridge space model is used in the calculation. The beams, towers, auxiliary piers are separated by space beam. And the backbone mode is used in the main beams. The relationship between the nodes and the stay cables is master slave relationship. The space bar element is used in the stay cable, and the nonlinear effect caused by the stage of cable is concerned by equivalent elastic modulus. In addition to the horizontal movement along the bridge and rotation around the bridge, the others are all master slave relationship. The boundary condition is fixed and connected at the tower foundation. The whole bridge is divided into 216 nodes and 213 units. The dynamic calculation model is shown in Fig.1.

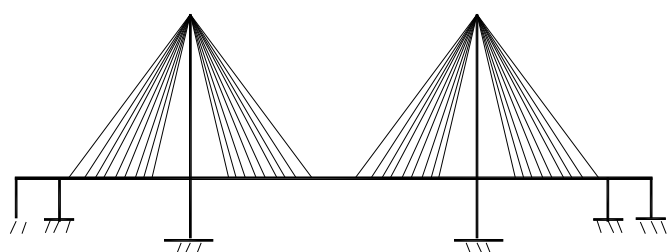

Fig.1 The dynamic calculation model

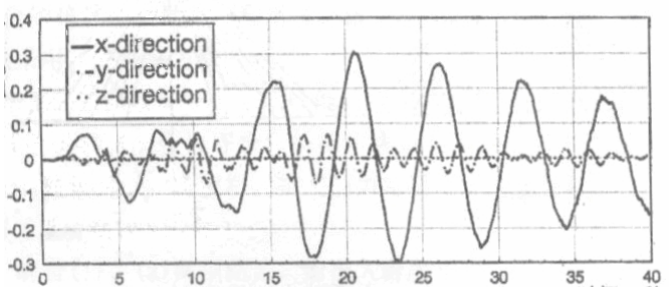

Fig.2 The time course of the displacement of the main girder

The analysis of dynamic characteristics: The first 7 natural frequencies, vibration modes calculated of the main bridge are shown in Table 1. It can be seen from the table that the calculation results are in agreement with the experimental results. The difference of the first order torsion vibration frequency is bigger, and which is related to the small torsion stiffness of the steel box girder. And the choice of backbone mode of the main beams will also bring some errors. Because the first order torsion vibration is closely related to the wind resistance of the structure, and which has little impact on the anti-seismic capacity of the structure. It can be considered that the selected model and its parameters are reasonable.

Table 1 The self vibration characteristics of the main bridge

\begin{tabular}{cccc}
\hline Number & Natural frequency $(\mathrm{Hz})$ & $\begin{array}{c}\text { Calculated self } \\
\text { frequency }(\mathrm{Hz})\end{array}$ & Vibration type \\
\hline 1 & 0.20 & - & Floating \\
2 & 0.50 & 0.45 & Vertical bending \\
3 & 0.68 & 0.72 & Transverse bending \\
4 & 0.69 & 0.63 & Vertical bending \\
5 & 0.73 & 0.96 & Reverse \\
6 & 1.11 & 1.14 & Vertical bending \\
7 & 1.26 & 1.29 & Transverse bending \\
\hline
\end{tabular}


Input ground motion: The artificial waves reflecting regional seismic geological structure and the characteristics of ground soil layer are often used in the anti-seismic time history analysis of the large span bridges. The artificial waves obtained from standard design response spectrum are used in the seismic time history analysis of the highway bridge. And the response spectrum is obtained from the seismic risk analysis of bridge site. In order to compare the calculated results, the two practical seismic records are also chosen, which are EI-Centro wave and Tianjin wave. The earthquake acceleration peak value is 144gal (probability of exceedance is 100 years 10\%). The waves are input from three directions, and the damping ratio is $2 \%$.

The time history analysis results: The nonlinear factors, initial internal force, effects, and geometric large deformation, etc, are taken in to account in the time history analysis. Under different ground motion input conditions, the response of the artificial wave is the biggest, and the Tianjin wave is the smallest. Under the artificial wave input, the time course of the displacement of the main girder is shown in Fig.2. On the whole, the main bridge seismic response is controlled by longitudinal direction.

Seismic performance evaluation: Tower section internal force: Under the action of artificial wave, the tower section moment My is $2.28 \times 105 \mathrm{kN} \bullet \mathrm{m}$, and dynamical axial force $\mathrm{N}$ is $3.15 \times 104 \mathrm{kN}$. It shows that the seismic action cannot control the bridge, and the tower section have enough strength.

The relative displacement between the main bridge and the approach bridge: Because the PTFE rubber bearings are used in the auxiliary pier of the main girders, and in influence of the longitudinal displacement of the main girders to the auxiliary piers, the displacement reaction of auxiliary piers is very small. The occurrence possibility of failing beams is small.

Interaction between main girder and auxiliary pier: In order to adapt to the connection of approach bridge, the relative displacement between the main girder and the auxiliary pier is allowed $35 \mathrm{~cm}$. The calculating seismic displacement response is $30 \mathrm{~cm}$. There will not be a collision between the main beam and the auxiliary pier. Since the maximum expansion displacement is $28 \mathrm{~cm}$, the expansion joint may be slightly damaged.

In conclusion, it can be considered that the bridge can ensure the seismic safety.

\section{Conclusion}

In this paper, according to the results of calculation of a bridge project, the earthquake disaster experience of bridge engineering at home and abroad, the following conclusions are obtained:

Tower foundation section has sufficient strength, and the earthquake action is not controlled.

The displacement at the joint between the main and auxiliary bridge is very small, and the possibility of beam failing is small.

The expansion joint between the main girder and the auxiliary pier may be minor damage.

The comprehensive analysis shows that the bridge can ensure the seismic safety.

\section{References}

[1] M.J.N. Priestley. Seismic design and reinforcement of bridge[M]. Beijing: People's Communications Press, 1997.

[2] Fan Lichu. Bridge seismic[M]. Shanghai:Tongji University Press , 1997.

[3] Liu Chunguang, Lin Hao. Research on push-over method for earthquake-resistant performance of bridge structure [J]. Journal of Dalian University of Technology:2005,45(3):395-400.

[4] Wang Dongsheng, Zhai Tong, Guo Mingzhu. Estimated seismic vulnerability of bridges by push-over method[J]. Word Information on Earthquake Engineering:2000,16(2):47-51. 